\title{
AULA DE HISTÓRIA: \\ EVENTO, IDEIA E ESCRITA
}

\author{
HISTORY CLASS: EVENT, IDEA AND WRITING
}

Helenice Aparecida Bastos Rocha ${ }^{1}$

\begin{abstract}
RESUMO: O artigo busca contribuir para o tratamento da aula e de seu planejamento como conteúdos na formação de professores de História. Para isso, dialoga com bibliografia historiográfica e pedagógica sobre o tema, considerando a especificidade dos conteúdos e objetivos da aula de História no ensino básico. Levando em conta a pluralidade constitutiva de alternativas didáticas para o ensino de história na escola, o texto se divide em quatro partes: a aula como unidade singular e rotineira, especificidades curriculares da história escolar e da organização do ensino na escola, o planejamento do ensino em diferentes escalas e o planejamento de sequencias didáticas como uma primeira escrita da história escolar que se realiza na aula.
\end{abstract}

Palavras-chave: Ensino de história. Aula. Planejamento. Tempo escolar. Sequência didática.

\begin{abstract}
This article seeks to contribute to dealing with lessons and their planning as content in History teacher's training. It establishes a dialogue with the historiographical and pedagogical bibliography about the subject, considering the specificity of contents and goals of History lessons in Elementary education. Because of the constitutive plurality of teaching alternatives, the text is divided into four parts: the lesson as a single and routine unit, curricular specificity of school history and of the organization of teaching at school, teaching planning in different scales, and the planning in didactic sequences as the first writing of school history which takes place in class.
\end{abstract}

Keywords: History teaching. Lesson. Planning. School timing. Didactic sequence.

\footnotetext{
1 Professora adjunta da Universidade do Estado do Rio de Janeiro (UERJ). Doutora em Educação pela Universidade Federal Fluminense (UFF). Conta com apoio Jovem Cientista de Nosso Estado, da FAPERJ, e do Prociência da UERJ, com o projeto Narrativas nos livros didáticos de História: entre diálogos e tensões.
} 


\section{Introdução}

Os licenciandos do curso de História chegam às disciplinas específicas de sua formação docente entre certezas e incertezas. Consideram que já sabem o que é a história a ser ensinada a seus futuros alunos, mas, na maioria das vezes, esperam que a disciplina de Didática do ensino de história, Ihes ensine como fazer. Ou seja, apesar do discurso pedagógico presente nas licenciaturas vir, há décadas, negando seu caráter estritamente técnico, os graduandos alimentam a expectativa de, ali, aprenderem como se faz. E se decepcionam quando seus professores afirmam que a diversidade constitutiva de turmas e alunado, especialmente as públicas, do ensino Básico exige a consideração de uma pluralidade de possibilidades didático pedagógicas.

Nessas disciplinas, ao chegar às aulas em que vão pensar sobre o planejamento de aulas, nova decepção. Seus professores insistem em que, de acordo com os referenciais historiográficos e pedagógicos que elegerem, seus objetivos de ensino e aprendizagem, para não falar dos conteúdos, serão diferentes. Ou seja, os professores afirmam que o planejamento não é uma questão apenas técnica, mas que mobiliza necessariamente toda a sua formação para que seja realizado de forma adequada.

De qualquer modo, com expectativas recíprocas atendidas ou não, o professor da disciplina de Didática ou Metodologia do Ensino de História precisa trabalhar com o planejamento de aulas como conteúdo específico de sua disciplina. Pensando nesta necessidade, este texto busca oferecer uma modesta contribuição para a formação do professor de História, no que se refere à aula considerada como evento singular e rotineiro, habitada pelas ideias de quem a concebe e realiza e pela escrita de seu planejamento. Por conta disso, o planejamento de aulas de história é tratado aqui como uma primeira escrita da aula de história. Chamamos para a conversa algumas contribuições do campo da didática e do currículo, considerando especificidades tais como seus conteúdos e objetivos correlatos e a organização escolar e da cultura que lhe é própria, na escola brasileira de hoje.

O texto se divide em quatro partes: a aula como unidade singular e rotineira, especificidades do currículo da história escolar e da organização do 
ensino na escola, o planejamento do ensino em diferentes escalas e o registro do planejamento em História em sequências didáticas.

\section{A aula: singular e rotineira}

O ponto de partida para este artigo é a aula de História como um momento singular e, ao mesmo tempo, rotineiro, de interação entre professores, alunos e os conhecimentos históricos, o que não pode ser desprezado quando se fala em planejamento de aulas. Singular porque único e delimitado, ao longo de um período maior - semana, mês, bimestre, ano letivo... Cada dia de aula em uma turma é único. Professores e um número expressivo de alunos realizam combinações imponderáveis de humor, disposição para estar ali, presença, aproximação ou distância biográfica dos conteúdos que serão tratados, bem como de sua abordagem.

Por outro lado, sessenta aulas de história (em média) ao longo do ano letivo constituem-se como rotineiras, pois a cada aula professores e alunos compreendem mais e melhor o que podem esperar uns dos outros na tarefa de, repetidamente - explicar, interpelar, ouvir, fazer tarefas, realizar provas, conversar e tantas outras coisas que constituem a rotina de uma aula. E essa compreensão mútua também vai mudando as formas de agir de professores e alunos, a cada aula. Assim, uma aula é um evento, em sua singularidade, e uma rotina, por tudo o que se repetirá ao longo do ano, em outros tantos eventos.

Visando o singular e o rotineiro, a aula requer um planejamento por parte do docente que a realizará junto com seus alunos. É o professor que vai estabelecer margens ao imponderável, administrando a interação com a turma, o período da aula e os conteúdos a serem ministrados e aprendidos. E essa administração envolve planejamento e replanejamento. Como as coisas (na interação própria da aula) tendem a acontecer diferentemente do que planejamos, precisamos desenvolver a capacidade de avaliar os acertos e os 
erros, para replanejar superando os limites que possuíamos antes e conferirmos previsibilidade ao imprevisível, na medida do possível. ${ }^{2}$

Que visibilidade temos conferido à aula como lugar do (im)previsível na organização das disciplinas das licenciaturas incumbidas de tratar do planejamento de aulas? Encontramos duas evidências de um lugar secundarizado. A primeira é a bibliografia que aborda diretamente o tema e a outra é a prática docente, acompanhada pelos licenciandos de História em seus estágios supervisionados.

Na bibliografia sobre o tema encontrada nas pastas de xerox de professores das licenciaturas encontramos insistentemente, desde 1990 e até os dias de hoje - livro Didática, de José Carlos Libaneo. A obra tem perenidade por conta de sua ampla aceitação e uso continuado por nós, docentes do ensino superior. Destaque-se que o objetivo aqui não é o de realizar a crítica dessa obra específica. Nem de exigir de uma obra com fins didáticos (portanto limitados) uma articulação que deveria ou poderia estar em nossas aulas, mas o de procurar captar na definição técnica da aula e de seu planejamento um fenômeno que permeia nosso pensamento e ação, qual seja, uma visão compartimentada.

Em busca do tema aula, no capítulo 8 a obra a define como "forma de organização do ensino". No capítulo 10, cujo título é o "O planejamento escolar", em uma seqüência lógica caminha do "plano da escola" ao "plano de aula", passando pelo "plano de ensino". E, nele, procura demonstrar a articulação entre esses diferentes planejamentos (Libâneo, 1992). Apesar dessas tentativas de articulação por inclusão, tem-se a impressão de que a aula, concretamente, está isolada do seu planejamento e de sua avaliação, do mesmo modo que o plano de aula só se articula artificialmente ao plano de ensino e ao planejamento escolar, descritos no livro em questão.

A segunda evidência do lugar secundarizado do tema aula na formação de professores está na própria prática do professor que é observada e funciona como modelo para o licenciando, em seu estágio supervisionado. Muitas vezes, se é possível perceber alguma continuidade entre as aulas, ela está mais no fato de ser o mesmo professor que ministra as aulas, ou a mesma turma que as

2 Jaime Cordeiro desenvolve de forma sintética aspectos diversos a serem considerados na relação pedagógica, que é constitutiva da aula. Cf. CORDEIRO, 2011, p. 66-79. 
recebe, ou pelo fato de o professor percorrer o mesmo caminho ou rotina a cada aula, ou uma eventual interrupção do conteúdo que continua na aula seguinte. No que se refere à continuidade do tratamento dos conteúdos, na aula de História, há ainda, mesmo que fracamente, o vínculo entre períodos históricos e a seqüência cronológica dos fatos históricos a ensinar, algumas vezes não explorados. Ou seja, para o licenciando do curso de História, os vínculos entre os conteúdos são construídos fora da aula, pelo seu próprio conhecimento da cronologia e tradição dos conteúdos históricos.

A partir dessa vivência teórica e prática, os licenciandos de estágio supervisionado têm elaborado uma concepção de que cada aula comporta o tratamento de um conteúdo específico, ou uma unidade em si mesma, o que é evidenciado em seus relatórios de estágio. Dessa maneira, quando chega o dia de ministrar sua aula prática - o graduando prepara uma aula que cabe naquele tempo específico de cinquenta ou noventa minutos, sem se preocupar com o conteúdo que veio antes e nem com o que vem depois (em termos de conteúdos abordados, objetivos de ensino e aprendizagem e até mesmo qual a aprendizagem anterior existente ou necessária). Utiliza o mesmo tipo de aula exaustivamente ministrada e criticada, a aula expositiva monolítica: Primeira República Brasileira, Grécia Antiga, Expansão Marítima.

Não está sendo feita aqui uma crítica ao trabalho realizado pelos professores das turmas de estágio e muito menos ao dos alunos de nossos cursos, formados por nós. O ensino e formação que vêm sendo produzidos são o resultado dinâmico de determinadas condições sócio-históricas que fogem ao escopo deste trabalho. A preocupação manifesta é com os efeitos da formação oferecida aos alunos das licenciaturas em História e as alternativas curriculares e didáticas que temos a esse quadro.

\section{O planejamento didático e as especificidades do ensino de história na escola}

Planejar aulas de História é concatenar aspectos diversos. Há a considerar as finalidades educacionais que estão no horizonte da disciplina, características 
do conteúdo a ser ministrado, do alunado e sua trajetória de aprendizagens, da escola e suas condições para a realização da aula, dos materiais disponíveis para viabilizar certas formas de ensino e aprendizagem e do próprio professor, com sua experiência de administração de cada um desses fatores.

Destaco, para a reflexão proposta aqui, os conteúdos em sua sequência e o tempo escolar existente para o ensino e aprendizagem desses conteúdos. De forma muito simplificada, planejar é distribuir conteúdos no tempo, estabelecendo formas pretendidas de ensinar e aprender.

Ao pensar nos conteúdos, na maioria das vezes, o que habita as mentes dos licenciandos e de uma parcela dos professores são os conteúdos da tradição escolar, de cunho informativo, conceitual e factual, a serem ministrados e avaliados a partir da exposição do professor ou pelo acesso a informações organizadas em livros, sites, plataformas. Entretanto, de acordo com a perspectiva pedagógica ou historiográfica, poderá existir uma conceituação diferente dessa tradição somente informativa e calcada apenas na transmissão. A proposição de Zabala (1998, p. 38-43) é considerarmos a existência de conteúdos de diferentes tipos: factuais, conceituais, procedimentais e atitudinais, o que estabelece o lugar do trabalho planejado com cada um deles.

Mesmo com restrições da natureza do objeto de ensino ou da tradição escolar no ensino de História, nas últimas décadas do século $\mathrm{XX}$, alguns autores do campo do ensino de História (KNAUSS, 1996, GRINBERG, 2000, CARDONA, 2002), e inclusive o documento dos Parâmetros Curriculares Nacionais de História, expressaram algumas possibilidades de transformação do ensino de História, apontando especialmente alternativas metodológicas da História a serem implementados na sala de aula. Entre elas, a realização de oficinas, pesquisa e estudos do meio por parte dos alunos do ensino fundamental e médio especialmente referidas a conteúdos de natureza procedimental.

Em História, como em outras disciplinas escolares, confere-se tradicionalmente visibilidade aos conteúdos factuais e secundariamente aos conceituais. E tratam-se os procedimentos como algo que os alunos já devem trazer prontos para a aula. Considerando a característica narrativa do conhecimento histórico, a organização curricular e dos programas em história que prevalece é a de orientação cronológica, conforme tipologia apresentada por 
Margarida Felgueiras para o caso português (1994). Assim, cada ano escolar deverá abordar certo período histórico e tratar predominantemente ou de forma integrada da história nacional ou mundial. ${ }^{3}$

Em termos de planejamento, a organização cronológica dos conteúdos trabalha ocultamente com a expectativa de pré-requisito temporal. Como exemplo, para um aluno estudar a Idade Moderna precisa ter estudado antes a Idade Média. Entretanto, se considerarmos a organização de programas por temas ou conceitos, bem como o acesso à história através de diferentes mídias e produtos culturais, tal expectativa se fragiliza, pois a lógica temporal é desestruturada. ${ }^{4}$

Considerando essas características da tradição curricular em História, o primeiro passo no planejamento será o de examinar o conjunto de conteúdos a serem aprendidos e ensinados em sua relação com o período escolar destinado para esse aprendizado. O ano letivo está dividido em semestres? Em bimestres? Em trimestres? Essa repartição prevista no tempo do ano letivo remete a períodos de início e de final, de provas, recuperação, lançamento de notas. Esses são rituais da cultura escolar que atuam como limites temporais de períodos em que grupos de conteúdos serão abordados e avaliados (FARIA FILHO, 2004).

Após a distribuição dos conteúdos no tempo do ano letivo e suas partes, há que considerar se o professor tem duas ou três aulas semanais para a disciplina, e se as aulas são agrupadas ou separadas. Aqui nos aproximamos da singularidade da aula como um período pequeno de tempo em que as coisas precisam acontecer. São 50 a 100 minutos, dos quais o professor descontará os minutos de entrada e saída, o fato de a aula ser a primeira ou a última do dia, o que contribui sobremaneira no humor e energia disponível para o trabalho de professores e alunos. Essas observações, que abordam o "miudinho" da aula, se aproximam do que podemos denominar de uma economia do trabalho docente e discente, ou uma ergonomia da aula (ROCHA, 2006), o que não é tratado corriqueiramente nos artigos acadêmicos pela urgência e magnitude de outros temas e questões educacionais e disciplinares.

3 Sobre a organização e distribuição de conteúdos na disciplina escolar História, cf. ROCHA; CAIMI, 2014.

4 Para conhecer a tipologia apresentada cf. FELGUEIRAS, 1994, p. 35. Em relação à crítica à permanência da organização cronológica do currículo em História, cf. STEPHANOU, 1998. 


\section{O planejamento em escala: do plano de curso ao plano de aula de história}

Ilmar Rohloff de Mattos estabelece uma analogia entre a escrita da história e a escrita da aula (2006). Em seu artigo, ele procura conferir visibilidade para o trabalho com a narrativa histórica por professores no processo da aula. Concordando com o autor, proponho que a escrita da aula seja considerada desde o momento do planejamento, o que envolve uma escrita efetiva, não apenas uma apresentação oral. Na verdade, que pensemos na escrita prévia da aula como condição para uma apresentação e condução oral na interação da aula que corresponda aos anseios do professor e seus alunos. Mas, quando começa essa escrita?

Sabe-se que hoje, pela legislação vigente, as escolas devem ter um projeto político pedagógico que, entre outras necessidades, deve incorporar o antigo plano de curso que era refeito a cada ano escolar. No projeto, esse plano ganha certa estabilidade e sua mudança envolve uma mudança do próprio projeto. No dia a dia, os programas muitas vezes são constituídos pela lista de conteúdos factuais dos livros didáticos. Assim, seja pelo plano de curso presente no projeto político pedagógico ou pelo "programa" presente nos sumários dos livros didáticos, tem-se um roteiro dos conteúdos a serem sucessivamente trabalhados ao longo do aluno letivo. ${ }^{5}$

Poderá caber ao professor ou ao grupo de professores da escola distribuir os conteúdos nos períodos já mencionados, visando o conjunto de práticas de ensino e aprendizagem que envolverão a avaliação e a atribuição de notas aos alunos, ao longo do ano letivo. Em algumas redes de ensino essa distribuição faz parte de orientações ao professor que vêm de outra instância, tal como no Currículo Mínimo em vigor no Rio de Janeiro.

Mas, após essa distribuição de conteúdos ao longo de um ano letivo e suas partes, quem organiza sua distribuição pelas aulas é o professor. E aqui nos aproximamos do que é mais específico para o professor e da escrita da aula

5 Com a entrada da Base Nacional Comum Curricular no circuito legal de exigências ao currículo escolar, tanto os livros didáticos quanto os planos de curso dos projetos político pedagógicos passarão por reformulações futuras. Para mais informações sobre esse documento e o processo de seu estabel3eciemnto, cf. o portal de acesso http://basenacionalcomum.mec.gov.br/\#/site/inicio 
desta disciplina escolar. Para além da distribuição dos conteúdos no tempo do calendário escolar, será necessário analisar os conteúdos em sua estrutura e decidir a melhor forma de abordá-los ao longo do tempo necessário e possível para o trabalho com eles (SHULMAN, 1989). Essa decisão exige que o professor saiba que aprendizagens espera que o aluno tenha, a partir do trabalho em aula com tal conteúdo.

Nesse momento voltamos às características dos conteúdos em sua relação com os objetivos de aprendizagem. Em uma visão mais limitada das possibilidades da formação histórica, se se estiver visando apenas o domínio cognitivo de conhecimentos factuais, possivelmente a interação expositiva (pelo professor, por um vídeo, por uma leitura) seja suficiente. Nesse caso, se almeja na avaliação que os alunos sejam capazes de replicar o que Ihes foi transmitido, como conjunto de informações. Se desejarmos que o domínio de informações habilite os alunos a fazer sua crítica, já estaremos em um terreno cognitivo de maior complexidade, que exigirá, seja pela interação verbal ou qualquer outra, que os alunos exercitem sua capacidade analítica e de julgamento. Se almejarmos que os alunos, a partir do domínio do conteúdo factual, sejam implicados, recolham para si elementos identitários da narrativa apresentada, precisaremos propiciar atividades em aula em que eles exercitem tais ações de subjetivação do conhecimento, em sua objetividade. E esse conjunto de atividades deverá fazer parte do planejamento das aulas, que pode se organizar de diferentes formas, contemplando rotinas diárias, sequências didáticas e projetos.

Nesse sentido, consideramos que fazer um planejamento do conjunto de aulas necessárias para o trabalho com determinado conteúdo, visando os objetivos de aprendizagem estabelecidos, se mostra mais interessante para o estabelecimento de uma direção para o trabalho docente e discente, para a produção de uma narrativa com princípio meio e fim, com argumentos que propiciem a compreensão e a problematização pretendida. É nesse sentido que viemos propondo a organização de sequencias didáticas problematizadoras para o ensino de história. 


\section{A sequência didática problematizadora: o que é a proposta}

A sequência didática problematizadora é uma alternativa de planejamento que leva em conta a especificidade dos conteúdos e de seus objetivos de aprendizagem ao longo de um período delimitado. Ela se encontra entre outras modalidades de organização da aula, tais como atividades de rotina, sequências didáticas e projetos didáticos. ${ }^{6}$ A sequência didática se diferencia de projetos e se aproxima, como concepção, das antigas unidades didáticas, pela sua vinculação com determinado conteúdo. ${ }^{7}$ Compreendemos que a sequência didática como alternativa para organização do trabalho em história apresenta as seguintes qualidades em potencial, considerando a dinâmica do trabalho docente que prevalece em nossas escolas:

1. Propicia ao professor e ao aluno a manutenção de visibilidade do todo no tratamento do conteúdo, na busca de atingimento de objetivos, enfim de seu desenvolvimento;

2. Permite o estabelecimento de estratégias didáticas alternadas entre o professor e o aluno, na construção da aprendizagem. Momentos em que o professor, a partir da natureza do conhecimento e do momento de abordagem alo longo da sequência, atua em um eixo predominantemente transmissivo - como nas exposições orais. E outros, em que predominará uma atividade mais construtiva por parte dos alunos - como em trabalhos de pesquisa, análise de fontes, apresentações resultantes de pesquisa e análise etc.;

3. No caso da sequência didática problematizadora, permite que a questão orientadora permaneça no horizonte de professor e alunos, ao realizar cada estratégia didática, conferindo sentidos e superando a burocratização do fazer de ambos, a cada aula.

${ }^{6}$ Conforme proposição de LERNER, 2005.

7 Sobre a sequência didática e outras modalidades de organização do trabalho didático, cf. $O$ quebra cabeças das modalidades organizativas. No portal Revista Escola: http://revistaescola.abril.com.br/formacao/quebra-cabeca-426234.shtml?page=0 Acessado em $1 / 10 / 2015$. 
O principal argumento para o segundo tópico é que, se grande parte do conhecimento histórico escolar está estruturado e precisa ser conhecido, é possível acessá-lo de forma que não seja exclusivamente através da exposição do professor, mas usando alternativas de busca de informações, como a pesquisa. Essa pesquisa também se voltaria à análise de fontes - material básico de análise do historiador - como exercício de interpretação e de crítica do aluno. Tais orientações representam uma contribuição interessante e produtiva ao ensino de História e a sua didática. O segundo argumento está na necessidade de considerar os conteúdos procedimentais como conteúdos a serem aprendidos e não pressupostos.

A sequência didática problematizadora, organizada em torno de um tema e de uma questão, também confere visibilidade a cada aula e a sua estrutura didática, articulando todas as estratégias em torno dessa questão. Considerando que se torna fundamental enfatizar o caráter seqüencial e imbricado das aulas, bem como pensando no desenvolvimento do assunto em torno de objetivos de ensino-aprendizagem, proponho os seguintes princípios ou pressupostos para as sequências didáticas problematizadoras:

1. O conteúdo a ensinar/aprender tem pontos, regiões ou momentos de maior dificuldade ou complexidade e outros de menor dificuldade. É preciso que o professor realize uma análise da estrutura global desse conteúdo para localizar esses pontos de maior complexidade, para então definir em que momentos da sequência didática ele fará exposições didáticas, em que momentos os alunos farão pesquisas de conhecimentos já estruturados, em que momentos analisarão documentos em busca de produzir conhecimento sobre a História e de tornarem-se melhores leitores de diferentes materiais;

2. Interessa ao professor buscar e/ou criar problematizações que fomentem a reflexão sobre as questões enfrentadas pelos homens do passado - o que pode representar o fio condutor da seqüência didática - e suas possíveis relações (de causalidade, ou de similaridade ou de diferença) com questões do presente; 
3. A História transita no campo da linguagem, interrogando-a - em suas diferentes formas de expressão - e produzindo o discurso historiográfico através dela. Assim, interessa dedicar especial atenção às diferentes linguagens (verbais e não verbais) que circulam na sociedade e que significam formas de apropriação do conhecimento histórico pelo aluno: documentação, patrimônio e museus, cinema, fotografia, entre tantos outros.

Nesta proposta o professor é extremamente atuante. A necessidade de um planejamento global e prévio fica muito clara. A seqüência não funciona sem esse planejamento. O professor precisa planejar toda a seqüência didática, e antes disso, analisar a estrutura do conteúdo quanto a sua complexidade - e aqui penso em Shulman (1986), com suas categorias de conhecimentos que o professor domina sobre os conteúdos - para então decidir onde entrar realizando suas exposições didáticas, onde é cabível um debate ou discussão, ou onde os alunos irão pesquisar bibliografia, apresentando seminários ou simpósios ou analisando documentos. Precisa orientar a preparação dessas apresentações, bem como conduzir as análises de fontes e organizar o seu registro. Outrossim, precisa avaliar a sua realização ao longo do desenvolvimento da seqüência, para corrigir o rumo do que estiver inadequado. Ou seja, diferentemente da aula isolada, que por sua atomização vai poupando os professores do investimento necessário em sua produção diversificada, a sequência didática exige um investimento de artesanato docente. E certamente esse pode ser um fator para sua não concretização, em tempos de vida docente tão corrida pela necessidade.

De modo semelhante, espera-se que, em uma seqüência didática problematizadora, o aluno se envolva, de modo a tomar para si o problema apresentado, à medida que seja uma questão a ser desvendada. Que alterne a busca e apresentação de informações e conhecimentos com o professor de modo responsável e cada vez mais competente.

Ao longo dos últimos dez anos, realizamos o exercício de elaboração de sequencias didáticas com os licenciandos do curso de História da Faculdade de Formação de Professores da UERJ. Esse período permite fazer uma avaliação da proposta em sua realização como planejamento e como forma de escrever a aula 
de História. Ou seja, como escrita preliminar de uma narrativa sobre determinado tema ou assunto.

Constatamos que o exercício de distribuição de aulas, conteúdos e estratégias, para além do planejamento de uma única aula se constitui como experiência formativa que mobiliza diferentes aprendizagens dos licenciandos, exigindo-Ihes considerar o tempo escolar, a relevância e complexidade dos conteúdos, que questões podem ser mobilizadoras do trabalho ao longo do desenvolvimento de uma sequência e, especialmente, a relação disso tudo com os objetivos de aprendizagem que poderão ser perseguidos. Esse exercício certamente extrapola a carga de conteúdos que eles terão aprendido ao longo de seu curso e pode ser mobilizador de capacidades que um professor necessita desenvolver ao longo de sua carreira.

A partir desse exercício de escrita de sequências didáticas, os licenciandos têm conseguido obter uma visão mais próxima, concreta e global de um processo de ensino de História, vendo a aula dentro desse processo, com sequências didáticas mais ou menos problematizadoras. Ou, pelo menos, entendem que é possível pensar em alternativas interessantes e articuladas para o ensino de História. Seus depoimentos apontam para percepção que a sequência requisita que eles pesquisem, criem, articulem conhecimentos que não imaginavam ser capazes de elaborar.

Uma das questões permanentemente postas é a de sua viabilidade em um contexto de carga horária reduzida para História, como componente curricular. As sequências que temos elaborado, conforme é possível perceber pelo exemplo a seguir, de uma aluna do curso de História, são relativamente extensas, comparadas à carga horária real existente. Este problema me levou a considerar alguns aspectos. Um deles é a falta de foco no que é fundamental na seqüência didática. A tendência que tem se mostrado predominante é a de o aluno montar a seqüência com todo o conteúdo factual da tradição curricular, relativa ao período cronológico estudado.

A proposta é, a partir da problematização, estabelecer o que é figura (relevante diante do problema examinado) e fundo (que passa a ser secundário). A competência requisitada aí é a mesma do pesquisador diante do mar de informações que tem diante de si e que precisa estabelecer o que é relevante e 
que passa a ser "dado" da pesquisa. Outro aspecto a destacar na questão do tempo despendido na execução da seqüência é que ela inclui conteúdos antes não considerados, no que se refere à História do presente. Neste sentido, é preciso ter clareza que, se estão sendo tratados conteúdos antes não considerados, o tempo escolar será usado e o que resta é procurar ter clareza da necessidade de seu uso.

Outra dificuldade, diretamente relacionada à anterior, é a de elaborar ou enxergar possíveis problematizações para a sequência. Muitas vezes os alunos tendem a confundir a problematização com os objetivos. Além disso, no planejamento da seqüência, há a tendência de concentrar sobre o professor, em diferentes momentos, a transmissão das informações. Ou seja, em enfatizar os procedimentos expositivos feitos pelo professor. O que evidencia a tendência à permanência de um padrão que foi vivenciado pelo aluno, a aula expositiva.

Ainda em torno da mesma questão, uma condição necessária para o sucesso do planejamento de antever onde é possível e desejável dividir a tarefa de buscar/apresentar/organizar informações com os alunos é a análise da estrutura do conteúdo como um todo e em partes. Assim, a montagem de um mapa conceitual e/ou das estruturas substantiva e sintática, segundo Shulman, pode ser de valia para os alunos do curso de graduação em História e em outros cursos, de modo a perceber com antecedência tais características do conteúdo. Em síntese, compreendo que a análise da estrutura do conteúdo é um exercício necessário de ser realizado conjuntamente com os professores especialistas nesses conteúdos, em nossas disciplinas.

Compreendo que as questões postas na realização da sequência evidenciam seu potencial problematizador para o próprio formador de professores de História, já que se cria ali um ambiente de questionamento das próprias bases da formação do professor.

Diante dessa avaliação, me parece que as sequências didáticas problematizadoras no ensino de História possuem um potencial formador no estabelecimento da aula como evento e como rotina e como módulos que podem se agrupar de formas diversas, para produzir aprendizagem. Elas contribuem para a escrita de uma história escolar que saia do enquadre de uma aula, mas mobilizem diversas aulas em torno de um propósito. E, antes dessa escrita, 
coloquem o licenciando para pensar em alternativas, em questões, em uma narrativa que conduza sua aula, a cada dia. Assim, bem como em outros processos de escrita, esse trabalho pode atuar fortemente como atividade formativa do futuro professor de História.

Apresento como Anexo 1 a formulação esquemática de uma seqüência didática elaborada por mim e utilizada em sala, para nossa discussão e referência para a produção de planejamento de outras seqüências didáticas. $E$ como Anexo 2 outra sequência didática, formulada por uma aluna do curso de História.

\section{Referências}

BRASIL. Parâmetros Curriculares Nacionais: história. Secretaria de Educação Fundamental. Brasília: MEC/SEF, 1998.

BURKE, P. Abertura: a nova história, seu passado e seu futuro. In: BURKE, Peter (Org.). A escrita da História: novas perspectivas. São Paulo: Ed. UNESP, 1992, p. 7-37.

A Escola dos Annales: 1929-1989: a revolução francesa da historiografia. São Paulo: Ed. UNESP, 1997.

CARDONA, F. X. H. Didáctica de las Ciencias Sociales, Geografía e Historia. Barcelona: Editorial GRAÓ, 2002.

CORDEIRO, J. A relação pedagógica. In: Universidade Estadual Paulista. Caderno de formação: formação de professores, didática dos conteúdos. São Paulo: Cultura Acadêmica, 2011, v. 2, p. 66-79.

FARIA FILHO, L. M. de; GONÇALVES, I. A.; VIDAL, D. G.; PAULILO, A. L. A cultura escolar como categoria de análise e como campo de investigação na história da educação brasileira. Educação e Pesquisa. São Paulo, v. 30, n. 1, p. 139-159, 2004.

FELGUeIRAS, M. L. Pensar a história, repensar o seu ensino. Porto: Porto Editora, 1994.

GRINBERG, K. et al. Oficinas de História: Projeto Curricular de Ciências Sociais e História. Belo Horizonte: Dimensão, 2000.

LERNER, D. Ler e Escrever na Escola: o real, o possível e o necessário. Porto Alegre: Artmed, 2005. 
LIBÂNEO, J. C. Didática. São Paulo: Cortez, 1992.

MATTOS, I. R. de. "Mas não somente assim!" Leitores, autores, aulas como texto e o ensino-aprendizagem de História. Tempo. Rio de Janeiro, n. 21, p. 15-26, 2006.

KNAUSS, P. Sobre a norma e o óbvio: a sala de aula como lugar de pesquisa. In NIKITIUK, Sonia L. (Org.). Repensando o Ensino de História. São Paulo: Cortez, 1996.

ROCHA, H. A. B. O lugar da linguagem no ensino de História: entre a oralidade e a escrita. 2006. 466f. Tese (Doutorado em Educação) - Universidade Federal Fluminense, Niterói, 2006.

ROCHA, H. A.; CAIMI, F. E. A(s) história(s) contada(s) no livro didático hoje: entre o nacional e o mundial. Revista Brasileira de História. São Paulo, v. 34, n. 68 , p. $125-147,2014$.

SHULMAN, L. Those who understand: Knowledge growth in teaching. Educational resaercher. n.15, v. 2, p. 4-14, 1989.

STEPHANOU, M. Instaurando maneiras de ser, conhecer e interpretar. Revista Brasileira de História. São Paulo, v.18, n. 36, p.15-38, 1998. 


\section{Anexo 1: Sequência didática problematizadora}

Tema: As portas de entrada e saída da cidade do Rio de Janeiro

Objetivo geral: Refletir sobre a cidade como espaço de circulação (produção, entrada e saída) de bens materiais e simbólicos. Será analisado o caso da cidade do Rio de Janeiro no contexto de chegada da família real (início do século XIX) e atualmente.

Problema: Todas as cidades são igualmente protegidas de influências externas? Como e o que circula entre elas? Através de que "portas"?

\begin{tabular}{|c|c|c|}
\hline Aulas & Conteúdos & Procedimentos \\
\hline 2 & $\begin{array}{l}\text { - Circulação de bens } \\
\text { na cidade ontem e } \\
\text { hoje. } \\
\text { Chegada da } \\
\text { família real no séc. } \\
\text { XIX. }\end{array}$ & $\begin{array}{l}\text { - Conversa dirigida. } \\
\text { - Arrolamento de informações e } \\
\text { questões; } \\
\text { - Exposição didática. }\end{array}$ \\
\hline 2 & $\begin{array}{l}\text { O espaço da } \\
\text { cidade: no século } \\
\text { XIX e hoje. }\end{array}$ & $\begin{array}{l}\text { - Análise de planta da cidade no } \\
\text { início do séc. XIX e atual; } \\
\text { - Combinação de passeio e roteiro. }\end{array}$ \\
\hline 2 & $\begin{array}{l}\text { - Chegada da } \\
\text { família real. } \\
\text { Impacto sobre a local: } \\
\text { população e } \\
\text { moradia, religião. } \\
\text { Tecnologia } \\
\text { meios de transporte } \\
\text { (navios). } \\
\text { A arquitetura } \\
\text { como fonte de } \\
\text { informações. }\end{array}$ & $\begin{array}{l}\text { - Análise de mapa; } \\
\text { - Visita à região da praça XV: } \\
\text { antigo porto, porto atual, Paço, } \\
\text { Museu Naval, igrejas, chafariz } \\
\text { Mestre Valentim, subida da ladeira } \\
\text { da Misericórdia, hospital da } \\
\text { Misericórdia, atual Museu Histórico } \\
\text { Nacional; } \\
\text { Comparação da arquitetura local } \\
\text { (colonial, do início do século XX e } \\
\text { atual). }\end{array}$ \\
\hline 2 & - & $\begin{array}{l}\text { - } \text { Registro de informações } \\
\text { levantadas no passeio, a partir }\end{array}$ \\
\hline
\end{tabular}




\begin{tabular}{|c|c|c|}
\hline & & $\begin{array}{l}\text { de fotografias de locais visitados; } \\
\text { - Organização de simpósio/ } \\
\text { seminário (pelos alunos) sobre } \\
\text { diferentes transformações } \\
\text { sofridas pela cidade no período } \\
\text { de estada da família real. }\end{array}$ \\
\hline 2 & - & $\begin{array}{l}\text { - Exercícios de consolidação da } \\
\text { aprendizagem - estudo dirigido. }\end{array}$ \\
\hline 2 & $\begin{array}{l}\text { Transformações da } \\
\text { cidade. }\end{array}$ & $\begin{array}{l}\text { - Simpósio/seminário (com análise } \\
\text { e uso de imagens). }\end{array}$ \\
\hline 4 & $\begin{array}{l}\text { As portas se } \\
\text { abrem e se } \\
\text { fecham? A Família } \\
\text { Real volta à } \\
\text { Europa. }\end{array}$ & $\begin{array}{l}\text { - Exposição didática; } \\
\text { - Leitura e estudo dirigido. }\end{array}$ \\
\hline 2 & $\begin{array}{l}\text { - As portas da } \\
\text { cidade hoje: } \\
\text { o que se produz } \\
\text { na cidade do rio de } \\
\text { Janeiro, o que chega } \\
\text { e o que sai? Por } \\
\text { onde? } \\
\text { Hoje nos afetam } \\
\text { fatores } \\
\text { internacionais? Do } \\
\text { mesmo modo como } \\
\text { acontecia naquela } \\
\text { época? Quais? }\end{array}$ & $\begin{array}{l}\text { - Leitura em dupla de reportagens } \\
\text { e recortes de jornal, busca de } \\
\text { respostas às questões colocadas; } \\
\text { - Discussão no grupo turma. }\end{array}$ \\
\hline
\end{tabular}




\section{Anexo 2: Sequência didática problematizadora}

Tema: Reforma Urbana na Cidade do Rio de Janeiro

Objetivo Geral: Avaliar os interesses envolvidos em uma reforma urbana, enfatizando o lugar da população desprovida de recursos materiais e seu deslocamento das áreas centrais da cidade. Será analisado o caso da Cidade do Rio de Janeiro, na virada do século XIX par o XX, no panorama da Abolição da Escravatura, da Proclamação da República e nos dias atuais.

\begin{tabular}{|c|c|c|}
\hline Aulas & Conteúdos & Procedimentos \\
\hline 2 & $\begin{array}{l}\text { - } \text { Abolição da Escravatura. } \\
\text { - Processo de implementação da } \\
\text { Republica. }\end{array}$ & $\begin{array}{l}\text { - } \text { Conversa Inicial; } \\
\text { - Leitura dirigida sobre a Lei } \\
\text { Áurea; } \\
\text { - Leitura dirigida de artigos } \\
\text { da imprensa do período; } \\
\text { - Exposição didática. }\end{array}$ \\
\hline 2 & $\begin{array}{l}\text { - O Positivismo e as idéias de } \\
\text { Ordem e Progresso. }\end{array}$ & $\begin{array}{l}\text { Análise de fontes: } \\
\text { - Avaliação do } \\
\text { discurso oficial, através da } \\
\text { apreciação dos depoimentos } \\
\text { de membros do governo e da } \\
\text { recém-instaurada burguesia; } \\
\text { - Observação de projetos de } \\
\text { "embelezamento" da } \\
\text { Cidade; } \\
\text { Análise de depoimentos de } \\
\text { Lima Barreto e João do } \\
\text { Rio, enfocando a critica a } \\
\text { "modernização" da cidade. }\end{array}$ \\
\hline 2 & $\begin{array}{l}\text { - A questão da saúde da cidade. } \\
\text { - O discurso dos higienistas. }\end{array}$ & $\begin{array}{l}\text { - Exposição didática; } \\
\text { - Análise de cartazes, } \\
\text { charges e artigos da } \\
\text { imprensa da época. }\end{array}$ \\
\hline
\end{tabular}




\begin{tabular}{|c|c|c|}
\hline 2 & $\begin{array}{l}\text { - A questão da moradia: O } \\
\text { contraste entre a Cidade Velha } \\
\text { e a Cidade Nova. } \\
\text { - Reforma Urbana - Introdução. }\end{array}$ & $\begin{array}{l}\text { - Análise da planta da cidade } \\
\text { do Rio de Janeiro no final } \\
\text { do século XIX e atual; } \\
\text { - Analise de fotografias da } \\
\text { época; } \\
\text { - Debate sobre os contrastes } \\
\text { das condições de vida das } \\
\text { camadas populares e das } \\
\text { classes abastadas; } \\
\text { Combinação de passeio e } \\
\text { Roteiro. }\end{array}$ \\
\hline 2 & $\begin{array}{l}\text { - } \text { Reforma Urbana. } \\
\text { - Mudança na paisagem da } \\
\text { cidade. } \\
\text { - Impacto sobre a população } \\
\text { local. }\end{array}$ & $\begin{array}{l}\text { - Visita ao centro da Cidade } \\
\text { do Rio de Janeiro: Paço } \\
\text { Imperial, Rua do Ouvidor e } \\
\text { adjacências, enfatizando os } \\
\text { lugares onde a elite do Rio } \\
\text { circulava no final do } \\
\text { Império. } \\
\text { Visita ao Morro da } \\
\text { Providencia: } \\
\text { destino dos moradores do } \\
\text { mais famoso cortiço da } \\
\text { época: o Cabeça de Porco. }\end{array}$ \\
\hline 2 & & 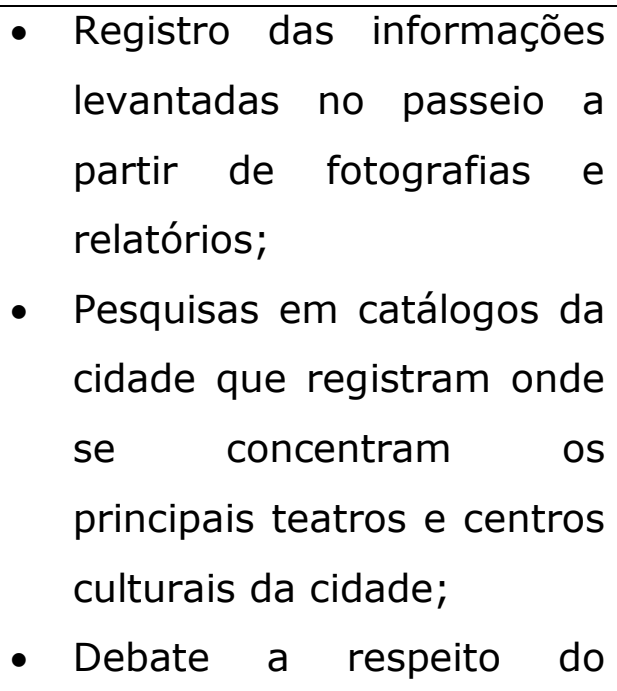 \\
\hline
\end{tabular}




\begin{tabular}{|c|c|c|}
\hline & & $\begin{array}{l}\text { afastamento da população } \\
\text { do centro da cidade. }\end{array}$ \\
\hline 2 & & $\begin{array}{l}\text { - } \text { Exercício } \\
\text { - } \text { Preparação para confecção } \\
\text { de um painel }\end{array}$ \\
\hline 2 & $\begin{array}{l}\text { - O progresso chegou para todo } \\
\text { mundo? } \\
\text { - Condições de vida da } \\
\text { população. } \\
\text { - A situação da saúde pública. } \\
\text { - Como vivem os moradores das } \\
\text { favelas, herdeiros dos cortiços } \\
\text { do século XIX? }\end{array}$ & $\begin{array}{l}\text { - } \text { Leitura dirigida de } \\
\text { - } \text { Reportagens; } \\
\text { relatórios e as fotografias } \\
\text { tiradas; } \\
\text { - } \text { Recuperação da pesquisa } \\
\text { - } \text { feita nos catálogos; } \\
\text { - } \text { Miscussão em grupo; } \\
\text { Montagem do painel. }\end{array}$ \\
\hline
\end{tabular}

